\title{
Llombart, Vicent: \\ Jovellanos y el otoño de las luces. Educación, economía, política y felicidad
}

Gijón, Ediciones Trea, 2012. 288 pp.

«Cómo hacer un buen libro» es un breve texto que Jovellanos redacta saturado por el volumen de libros que ya en el siglo XVIII llegaban a publicarse -«la manía de hacer libros ha llegado a tocar en furor»)-, e irritado por la mala calidad de muchos de ellos, en un tiempo en que, dice, brillaba por doquier el «desamparo del mérito» y una vergonzosa «libertad del charlatanismo». De hecho, apostaba ciento contra cinco a que de los millares de millares de libros nuevos que se «traficaban» en la feria del libro de Leipzig, por cada cinco buenos había noventa y cinco malos.

Y como esta reseña se ocupa de un libro sobre Jovellanos, quien, además, fue activo censor de la Academia de la Historia, bien podemos someter Jovellanos y el otoño de las luces a los criterios que el propio Jovino establecía y dejar que él mismo juzgue la obra, a sabiendas de que era un censor exigente: arrancaba Jovellanos aquel texto afirmando que «Nada es tan fácil como hacer un libro, pero nada es más difícil que hacer uno bueno. Con escribir por la mañana lo que se ha soñado por la noche, con repetir lo que otros han dicho o decir de otra manera lo que se ha dicho de mil, en fin, con llenar papeles con reflexiones triviales, hechos comunes o ideas confusas e incoherentes, y con citas y citas de autoridades inútiles, creen algunos que está cumplida la tarea. La de hacer un libro sí. Pero hacer un buen libro, jésta sí que es empresa ardua y penosa!».

La primera exigencia de Jovellanos para hacer un buen libro es «entender bien, bien la materia». Sería fácil solventar este punto diciendo que el profesor Llombart, catedrático de pensamiento económico de la Universidad de Valencia, es uno de nuestros dieciochistas más reconocidos, editor de los volúmenes de escritos de asunto económico de las Obras Completas de Jovellanos y Campomanes, y autor de un centenar de artículos sobre el siglo XVIII.

Pero la cuestión dieciochesca, y jovellanista, es de más enjundia. Por un lado, la actual especialización de los estudios conduce en ocasiones a una excesiva fragmentariedad, en que cada quien trabaja y cuida su árbol con esmero pero sin alcanzar a dar una visión del bosque; y no se puede entender al Jovellanos economista sin conocer 
al Jovellanos literato, político, o pedagogo. No es el caso de un volumen cuya virtud, una de las principales, es que abarca y enlaza educación, economía y política en una fructífera metáfora, la del «círculo virtuoso de la Ilustración», a que me referiré más adelante.

Por otro lado, Llombart sitúa el pensamiento de Jovellanos en el del siglo y en el ámbito europeo; matiza cómo ese pensamiento cambia con los años y según el contexto, por conformarse a lo largo de tres décadas en que el país transita desde el Antiguo Régimen a la preparación de las Cortes de Cádiz, vislumbrando a lo lejos las incendiarias luces de la revolución; y apunta cómo ese pensamiento está marcado, además, por unas circunstancias personales que cambian, en que median años de política activa, un destierro, un efímero ministerio y un encarcelamiento de siete años. En este volumen, cada afirmación aparece matizada por otras del propio Jovellanos y de ilustrados de referencia y queda situada en su contexto, tanto personal como español y europeo. No es difícil concluir, ahora sí razonadamente, que Llombart conoce, bien bien, como dice Jovellanos, la materia.

La segunda condición de Jovellanos es que «No basta saber perfectamente una ciencia, si sólo se dice lo que está ya dicho mil veces. El que así escribe, en vez de hacer un bien al público, le sobrecarga, le oprime con un libro de más».

Esta es cuestión complicada. Tras el bicentenario, después de congresos, exposiciones, catálogos, ciclos de conferencias y publicaciones diversas, habrá quien se pregunte ¿y después de todo esto, otro libro sobre Jovellanos? En este sentido, es evidente que las reflexiones sobre Jovellanos no arrancaron precisamente con los bicentenarios; venían de mucho antes -en 1812 publica Antillón su biografía- y es lógico que prosigan más allá del 2011, por ser Jovellanos paradigma de la Ilustración española, el clásico de nuestra Ilustración. Digamos que los dieciochistas, simplemente, siguen su camino al margen de los centenarios. En todo caso, aquí no se dice lo que está «dicho mil veces». Y este libro hace avanzar la frontera del conocimiento, porque, partiendo de una metodología científica construida sobre hipótesis realistas y criterios contrastables y, sobre todo, aportando nuevas interpretaciones, contribuye a la mejor comprensión de la obra y de las visiones de Jovellanos. No nos oprime Llombart, como dice Jovino, con un libro «de más».

Su tercera condición tiene que ver con la síntesis y la divulgación. Dice Jovellanos: «Es imposible llenar un libro de verdades nuevas, pero no es imposible, aunque sí muy difícil, exponerlas mejor. Despojarlas, en cuanto sea posible, del aparato científico, ordenarlas, reducirlas a la mínima expresión, sin perjuicio de la claridad. He aquí todo el secreto del método; he aquí lo que está por hacer; y he aquí lo que fácilmente estaría hecho si el orgullo científico no prefiriese la gloria de lucir a la de ser útil».

Vicent Llombart parece haber querido conscientemente aligerar el académico aparato, todo ese rimbombo de notas y citas y jerga oscura, en aras de la utilidad que le exige una colección sólida pero no reducida exclusivamente al ámbito investigador, como es «La Olmeda». Evidentemente, no se trata de que la labor de investigación no se haya realizado -se ha realizado en decenas de publicaciones previas-, sino de que se simplifica aquí el ingenio formal que suele acompañarla en aras de la claridad y la 
utilidad. Sólo puede simplificar el que es consciente de la complejidad. No se ha cumplido, por tanto, con la barroca idea de lucir, sino con la idea, tan ilustrada, de ser útil.

La cuarta condición de Jovellanos está relacionada, no ya con los contenidos, sino con la estructura: «No basta entender bien la materia de que se escribe, es necesario meditar profundamente lo que se ha de decir, penetrarse íntimamente de todas sus relaciones. No todos los que saben una materia son capaces de ordenarla. Hay talentos despiertos para la comprensión de la verdad y dormidos para su ordenación. Unos colocan el conocimiento como las nueces en un saco, otros como los eslabones en una cadena. Esto a la verdad no es dado a todos. Acaso en éste más que en otro punto son inmensamente desiguales los talentos».

Ordenar, esa es la clave de este libro. No acumular información, como las nueces en un saco, sino ordenar conocimientos, como los eslabones de una cadena. Pero para eso hay que dar con las claves que relacionan una obra amplísima y de temática tan variada como la del asturiano.

Hay una metáfora central que antes mencioné, el círculo virtuoso de la Ilustración, que es clave y definitiva para entender el núcleo duro del pensamiento de Jovellanos: qué tienen que ver en él la economía, la política, la educación y la felicidad pública, ese tan vapuleado hoy, estado de bienestar.

Según Llombart, en el pensamiento de Jovellanos, la economía, en tanto ciencia, aporta el instrumental preciso para diagnosticar los males que alejan a España de Europa; una vez acotados los «obstáculos», corresponde a la política establecer líneas de actuación y prioridades. A tales conclusiones habría llegado Jovellanos especialmente a partir de la experiencia acumulada en los años de su destierro gijonés, momento en que alcanzará tres conclusiones relevantes: la primera, que la dotación de recursos productivos -materias primas, capitales, trabajo-, siendo condición necesaria, no es requisito suficiente para el crecimiento económico; en consecuencia, y es la segunda conclusión, que el marco institucional y político - tanto si obstaculiza como si apoya- es determinante para que aquellos recursos se utilicen de forma eficiente. Por esa vía, Jovellanos llega a la tercera conclusión, que la fuente de todo cambio es la instrucción, en una doble dirección: la educación es fuente de productividad, de innovación, de ciencias útiles y, al tiempo, es la mejor garantía tanto para el control de las instituciones y la gobernanza política, a través de la opinión pública, como para que éstas ofrezcan incentivos, seguridad y certidumbre a largo plazo y faciliten el compromiso de los agentes económicos con el desarrollo. En el horizonte del círculo virtuoso está siempre la felicidad pública que, como el propio Jovino se encargará de matizar, no aparece como lejana utopía de orden exclusivamente moral, sino como una deseable e inevitable conquista individual y social: el estado del bienestar en que pueden ser felices los ciudadanos. Así, Llombart dota de coherencia y unidad a unos escritos, los de Jovellanos, sólo aparentemente dispersos o heterogéneos.

Resta aún una condición más para hacer un buen libro: «La intención del escritor ha de ser desinteresada». No abundaré en este asunto. Las interpretaciones sobre Jovellanos pueden ser muchas, y pueden los especialistas disentir, pero en ningún caso serán de recibo aquellas interpretaciones que han transgredido la ética de la investi- 
gación forzando los argumentos hasta descontextualizar la obra de Jovellanos para utilizarla al servicio de las más variopintas causas. El maestro de dieciochistas, Ernest Lluch, con quien Llombart inició hace décadas su investigación doctoral, lamentaba en el que sería uno de sus últimos escritos antes de su asesinato, el proceso de «extorsión y de falsificación» al que había sido sometida la obra de Jovellanos. Llombart recorre todos los Jovellanos que han sido y analiza quién los construyó y con qué motivo lo hizo. Este asunto ocupa buena parte del libro, y sólo por eso ya es recomendable su lectura, no sólo para quien quiera acercarse a Jovellanos, sino para cualquiera interesado en estas operaciones de construcción de la historia.

A estas cinco condiciones, parece que cumplidas, cabe añadir una más, en que Jovellanos insiste cuando se trata de textos propios o del Real Instituto cuya edición supervisa y que él quiere editados en Asturias, donde la imprenta entonces distaba de ser un ingenio de $\mathrm{I}+\mathrm{D}+\mathrm{I}$, y que no es otro que el que las obras han de estar bien editadas, «han de publicarse con la dignidad que la obra requiere», porque así "se medirá nuestra instrucción y nuestra diligencia y sólo de ellas depende nuestra reputación». Sólo decir que el buen hacer de Ediciones Trea ha quedado refrendado en el último ranking nacional del Grupo de Investigación de Evaluación de Publicaciones Científicas (EPUC) del CCHS del CSIC, encargado de la evaluación científica del área de Humanidades y Ciencias Sociales, donde esta editorial asturiana alcanza el puesto 12 de 142 en la disciplina de Historia y el 28 de 201 en el ranking general de editoriales españolas.

Parece que, revisados todos los criterios de Jovellanos, sólo cabe felicitar a quienes se han empeñado en llevar a cabo esta empresa: que el libro está escrito por alguien que conoce bien, bien la materia, que es capaz de explicarse sin jerigonza científica, que hay novedades, que hay método, que no hay intencionalidad espuria, que es útil y que está bien editado. Probablemente su examen habría merecido un informe parecido a este otro, que Jovellanos emitió de un libro que le pareció bueno: «Por tanto soy de dictamen que la obra es muy digna de la luz pública, tanto por la excelencia y novedad de su materia, cuanto por el orden y claridad con que está expuesta y la pureza del estilo. Por esto, el Consejo de Castilla, puede conceder la licencia que se solicita».

Elena de Lorenzo Álvarez

IFES.XVIII (Universidad de Oviedo) 